\title{
Adverse outcome pathways - development and potential regulatory application
}

\author{
Vias de desfecho adverso - desenvolvimento e potencial \\ aplicação regulatória
}

Thania Rios Rossi Lima ${ }^{1, *, \# ~(D) ~}$

Nathália Pereira de Souzal,\# iD

Lílian Cristina Pereira ${ }^{1,11}$ (iD

João Lauro Viana de Camargo'
Center for Evaluation of Environmental Impact on Human Health (TOXICAM), Department of Pathology, Universidade Estadual Paulista, Botucatu, SP, Brazil

" Department of Bioprocesses and Biotechnology, School of Agricultural Sciences, Universidade Estadual Paulista, Botucatu, SP, Brazil

* Equally contributed to the drafting of the manuscript.

\section{* E-mail: thania.lima49@gmail.com}

Received: Dec 07, 2020

Approved: Apr 26, 2021

\begin{abstract}
Introduction: Over the last two decades, chemical safety assessment and regulatory toxicology have progressed from empirical science based on direct observation of apical adverse outcomes in whole organisms to a predictive practice that infers outcomes and risks on the basis of accumulated understanding of toxicological mechanisms and modes of action. Objective: To provide general concepts on how Adverse Outcome Pathways (AOPs) are developed and examples related to skin sensitization, endocrine disruption, and mitochondrial dysfunction. Method: Narrative review based on data of the scientific literature relevant to the theme addressed and on the experience of the authors. Results: An AOP framework provides a systematic approach to organize knowledge about mechanisms of toxicity that may inform analytical domains in regulatory decision-making. AOPs are open structures that may indicate not only data gaps in the understanding of a toxicity process, but also testing procedures that will generate the necessary knowledge to fill those gaps. Every AOP should be continuously refined through the collaborative efforts of the scientific community. Depending on the amount and detail of information that is successively inserted, AOP may progress from the stage of a putative AOP to the stages of qualitative and quantitative AOPs, which are more fit-for-purpose to support regulatory decision-making. Conclusions: Continuous collaboration between AOP developers within the scientific community and the regulatory corps toward the development of this mechanistic structure will support the advancement of toxicological sciences, regardless of its immediate application for regulatory purposes.
\end{abstract}

KEYWORDS: Adverse Outcome Pathways; Hazard Assessment; Mode of Action; Risk Assessment; Regulatory Toxicology

\section{RESUMO}

Introdução: Durante as duas últimas décadas, a avaliação da segurança química e a toxicologia regulatória evoluíram de uma ciência empírica em grande parte baseada na observação de desfechos adversos em órgãos e ou organismos inteiros para uma prática preditiva que infere desfechos e riscos a partir do conhecimento acumulado sobre mecanismos e modos de ação toxicológicos. Objetivo: Discorrer sobre como as AOPs são desenvolvidas e fornecer exemplos relacionados à sensibilização cutânea, desregulação endócrina e disfunção mitocondrial. Método: Revisão narrativa baseada em dados da literatura científica relevantes para o tema abordado e na experiência dos autores. Resultados: A estrutura conceitual denominada AOP (do inglês, Adverse Outcome Pathway) permite uma abordagem sistemática do conhecimento disponível sobre mecanismos de toxicidade que pode subsidiar a tomada de decisões regulatórias. AOPs são estruturas abertas que podem indicar lacunas de dados para a compreensão de determinada via patogenética de toxicidade, de modo que podem ser continuamente aperfeiçoadas por esforços da comunidade científica. Dependendo das informações sucessivamente inseridas, as AOPs podem passar do estágio de uma AOP hipotética para os estágios de AOP qualitativa e AOP quantitativa, sendo este último o mais adequado para 
subsidiar decisões regulatórias. Conclusões: A colaboração contínua entre os desenvolvedores de AOPs dentro da comunidade científica e os corpos regulatórios para o desenvolvimento dessa estrutura mecanicista apoiará o avanço das ciências toxicológicas, independente de sua aplicação imediata para fins normativos.

PALAVRAS-CHAVE: Vias de Desfecho Adverso; Avaliação do Perigo; Modo de Ação; Avaliação do Risco; Toxicologia Regulatória

\section{INTRODUCTION}

The fast progression of the horizons of toxicological sciences, the increasing number of chemicals requiring safety assessment, and the social-ethical pressure on putting the $3 R$ s principles into practice during animal experiments ${ }^{1}$ have stimulated changes in toxicity testing, assessment frameworks, and regulatory toxicology $^{2,3}$. Efforts have been focused on moving away from extensive toxicity testing based on phenotypic responses in laboratory animals toward a mechanistic pathway-based approach that relies mostly on combining high-throughput and high-content data from in vitro assays, such as cell-based assays, with computational modeling (based on data generated in vivo) to predict toxicological effects of concern ${ }^{3,4,5}$.

A major step in this direction was taken in 2001 when the International Programme on Chemical Safety (IPCS) proposed the mode-of-action (MoA) framework ${ }^{6,7,8,9}$. The MoA framework causally correlates key events (KEs) along a linear biological pathway that spans from the initial chemical interaction to the adverse effect, to provide a detailed mechanistic description of the process $^{6,7,9}$. The adoption of MoA frameworks has encouraged the development of alternative testing methods and has helped to prioritize higher tier toxicity tests for chemicals with higher potential to promote adverse outcomes (AOs), which are suitable to inform risk assessments ${ }^{8,10}$.

As the process of toxicological testing refinement and interpretation advanced, the National Academy of Sciences (NAS) introduced the concept of "pathways of toxicity" in $2007^{11}$. This concept was first formalized as a system to support improved ecological risk assessment by grouping the existing ecotoxicological knowledge generated by in vivo, in vitro, and in silico toxicological studies ${ }^{11}$. Given that the Adverse Outcome Pathway (AOP) framework concept also refers to human health, the adoption of alternative methodologies (e.g., in vitro assays that employ cell systems relevant to human biology and computational models) has been proposed because they can help to evaluate not only specific apical adverse effects, but also the altered biological pathway triggered by chemical exposure ${ }^{12}$. The NAS emphasized the need to develop assessment approaches that make the best use of existing knowledge to focus on targeted search for critical new knowledge, while minimizing dependence on resource-intensive testing approaches ${ }^{11}$.

The definitions and practices of MOA and AOP frameworks commonly overlap; however, MoA represents a specific chemical description up to the organ level, whereas AOP is generalizable to any chemical focusing on a given molecular initiating event (MIE) that can lead to an $\mathrm{AO}$, which can be extended to the populational level. In addition, KEs in an AOP do not necessarily provide a comprehensive molecular description of every aspect of the underlying biology, which is in contrast with MoA ${ }^{13}$. Thus, in the same way that AOPs can serve as a starting point for MoA analysis of specific chemicals, MoA can also be used as basis for AOP development ${ }^{12,14,15,16,17,18}$.

In 2013, the Organisation for Economic Co-operation and Development $(\mathrm{OECD})$ proposed a formal resource to develop AOPs under the guidance of the Extended Advisory Group on Molecular Screening and Toxicogenomics (EAGMST), which also provides a public available inventory of existing AOPs ${ }^{19}$. The United States Environmental Protection Agency (U.S. EPA) and other organizations have collaborated with the OECD in the development of the AOP Knowledge Base (AOP-KB; https://aopkb.oecd.org/index.html; https://aopkb.oecd.org/), a portal that houses the official copy of all OECD-endorsed AOPs ${ }^{20,21}$. The AOP-KB covers four elements: AOP-Wiki (https://aopwiki.org/), Effectopedia (tool for AOP visual exploration and development; https://www.effectopedia.org/), AOPXplorer (computational tool that enables automated graphical representation of $A O P$ s and networks - under development), and the Intermediate Effects Database (IEDB; host chemical-related data and information on how individual compounds trigger an MIE and KEs - under development). Through the AOP-Wiki, any individual can submit an AOP proposal either to the Society for the Advancement of Adverse Outcomes Pathways (SAAOP), which reviews and refines AOPs in the early stages of development, or to the OECD AOP Development Work Plan. In this last instance, the proposal is internally reviewed by the EAGMST and then subjected to an external review by international experts. Once the AOP is considered scientifically sound, it is submitted to the OECD Working Group of National Coordinators (WNT) and the OECD Task Force on Hazard Assessment for endorsement and is finally posted as a reviewed AOP $22,23,24,25$. The USEPA Distributed Structure-Searchable Toxicity (DSSTox) database, which houses over 875,000 curated compounds related to toxicity tests, literature, health effects, and chemical/ structural/analytical information ${ }^{26}$, is a public tool that can aid AOP development. Although about 359 AOPs have been included in the AOP-Wiki to date, few of them (around 16, $4 \%-5 \%$ ) have been completely developed (high-confidence data) or endorsed by the $O E C D$, which is a challenge that has to be overcome during the process of AOP acceptance for regulatory purposes ${ }^{27}$.

This article aims to provide the scientific and regulatory communities with an overview of the principles that rule AOP development and applications in toxicological testing and assessment, so that these communities can keep up with the current developments in risk assessment and regulatory decision-making practices. 


\section{METHOD}

This narrative review allows the update of knowledge and identification of gaps to be explored on the theme addressed in a non-systematized way. It was constituted by the steps of literature search and interpretation by the authors, based on the following guiding questions: How to develop AOPs? Can AOPs be applied for regulatory purposes?

A search was carried out on the following databases: PubMed, Latin American and Caribbean Literature in Health Sciences (LILACS), Embase, Scientific Electronic Library (SciELO), Scopus and Web of Science, using the descriptors: ("Adverse Outcome Pathways") AND (Development) AND ("Potential Regulatory Application"). Studies that presented relevance with the theme were included in this review.

\section{RESULTS AND DISCUSSION}

\section{AOP concept and development}

An AOP framework is a sequence of successive causally related events leading to an in vivo apical $A O$ that is of interest to human and environmental health and may inform regulatory decisions ${ }^{13,18,20,21,22}$ (Figure 1). An AOP framework integrates and organizes data of different biological levels, increases understanding of causal links between KEs, and allows detection of knowledge gaps along the toxicity pathway. Data retrieved from the literature and data coming from newly performed experiments support the descriptions of MIEs, KEs, and AOs. Key event relationships (KERs) define structural and functional relationships between two KEs ${ }^{13}$. If a previous KE (upstream) is altered to a sufficient degree, predictable changes can be expected in the downstream succeeding events ${ }^{15,28}$.

Because the series of KEs do not always provide a comprehensive description of the underlying biological process, a limited number of KEs should be selected, normally on the basis of the existing information, to conceive an AOP to support assessment of the Weight-of-Evidence (WoE) in a regulatory context ${ }^{29}$.
KE descriptions should include the evidence that the identified $\mathrm{KE}$ is essential for the AOP, the indication of the assays that can characterize the $\mathrm{KE}$, its biological organization level (from molecular or cellular up to organ, individual, or populational level), and the taxonomic applicability, i.e., indication of how conserved the $\mathrm{KE}$ is across the species of concern ${ }^{30}$. Any type of information - in silico, in vitro, or in vivo data - can be added to an $\mathrm{AOP}^{30,31,32}$. Systematic organization of the available knowledge into AOP frameworks is informative and operational and may help to direct the design and development of computational prediction models ${ }^{33}$.

Five core principles of AOP

Although no universal strategy for AOP development exists, at least five core principles should be kept in mind to produce a consistent AOP $16,30,34$.

\section{AOPs are not chemical-specific}

Any stressor that triggers an MIE can potentially induce the chain of downstream causally related KEs that are represented in an AOP. Accordingly, a defined AOP is not specific for a determined chemical. Once AOPs are developed, they can be used to predict the AOs of other chemicals that have at least some molecular mechanisms (MIE) and biological interactions (KEs) that adjust to that AOP. Provided that the respective information on exposure and toxicokinetics/toxicodynamics are available, that $A O P$ can ultimately have regulatory applications ${ }^{35,36,37,38}$, as further indicated in this article.

\section{AOPs are modular}

An AOP framework needs to be clear and easy to understand and to apply. It must also offer flexibility to accommodate new data with varying levels of detail. Therefore, AOPs are modular structures, which means that each AOP can be broken down into its fundamental units, KEs and KERs ${ }^{30,36}$.

\section{AOPs are pragmatic units}

AOPs provide a structured way to describe one of the possible pathways following a specific MIE that results in a given $\mathrm{AO}$, not

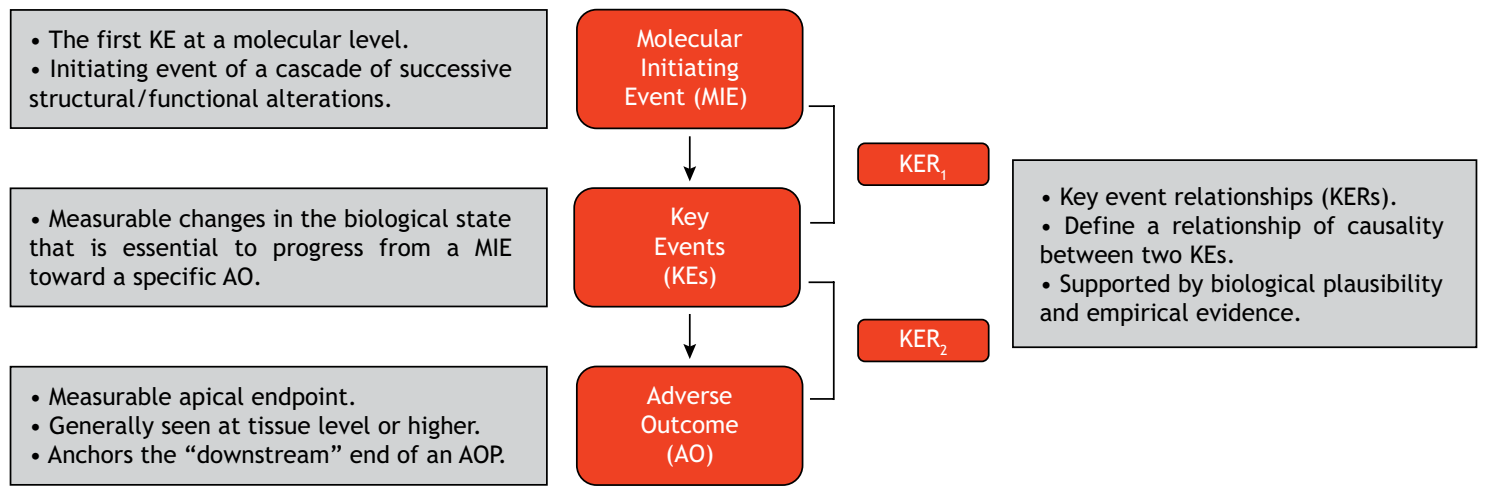

Source: Adapted from Organisation for Economic Co-operation and Development (OECD), $2016^{13}$.

Figure 1. Structure of an Adverse Outcome Pathway (AOP). An initial molecular interaction between a chemical and a biological system (molecular initiating event, MIE) is followed by units of key events (KEs) and the corresponding key event relationships (KERs), eventually leading to a verifiable apical adverse outcome (AO). 
intending to describe every possible pathway from point $A$ to point $B$; rather, it is a single route acting as the simplest functional unit of prediction ${ }^{30,36}$.

\section{AOP networks will emerge and are the basis for prediction}

A single molecular perturbation (MIE) can lead to more than one route of system failure and can thus reveal different AOPs. Consequently, multiple AOPs can share one or more common KEs and KERs, which results in the emergence of AOP networks. Analysis of AOP networks may show unexpected biological interactions, which imply in a wider interpretation of the modulation that determined that toxicological pathway. These multiple interactions indicate that AOPs occur in a context of systems biology $\mathrm{y}^{30,36,39}$.

\section{AOPs are living documents}

AOPs are not static; that is, they have the potential to evolve over time as additional knowledge becomes available. AOP developers can focus on developing AOPs that relate to their expertise, but they count on other developers to add branches to the AOP network as they contribute to the AOP-KB ${ }^{30,36}$.

\section{Fit-for-purpose: AOP for regulatory decisions}

Evaluating the potential contribution of a certain AOP to regulatory decision-making depends on the WoE for the hypothesized pathway, including consistency of the supporting data and the level of confidence on the KEs and KERs based on biological plausibility. In other words, this evaluation relies on expert evaluation of criteria such as the AOP stage (see next item), level of complexity and confidence, and assay validation, which may also be provided by external reviews $s^{27,31}$.

For WoE assessments to sustain a reliable AOP evaluation, the OECD proposed five key questions ${ }^{29,32}$ : Is the AOP well characterized? Is the AOP specific to certain tissues, life stages, or age classes? Are the MIE and KEs causally linked to the AO? Are the MIE and KEs expected to be conserved across the species? What are the limitations of the AOP? These questions should be preferentially supplemented by others based on the Bradford Hill's viewpoints for causality ${ }^{40}$.

\section{AOP stages}

On the basis of the supporting evaluation, AOPs are classified into three different stages of development. As the amount and quality of data supporting the WoE increases, an AOP goes from the putative to the qualitative and from the qualitative to the quantitative stages ${ }^{30}$, defined as follows:

a. Putative AOPs are characterized by hypothetic KEs and KERs, which are supported by incomplete biological plausibility or statistical inference as a result of data gaps and uncertainties.

b. Qualitative AOP have KEs supported by descriptions of how they can be verified and KERs supported by empirical data, but without relevant information for consistent transition from one KE to another. c. Quantitative AOPs contain precisely characterized KEs and KERs, supported by quantitative information that allow the magnitude and duration of change in sequential KEs to be predicted. These AOPs can also predict dose-response ${ }^{27,30}$.

\section{Level of $A O P$ complexity - $A O P$ networks}

AOPs are first developed in a linear format (Figure 1) to show progression from an MIE to an AO. AOP connections can occur over time due to shared KEs, to culminate in a network format that increases data complexity ${ }^{27,39}$.

\section{Confidence in the $A O P$}

The level of confidence varies from low to moderate and high and is associated with a WoE approach that considers biological plausibility, essentiality, and empirical evidence $\mathrm{e}^{3,27,40,41}$.

\section{External review of the $A O P$}

The possible statuses of an AOP in the AOP-Wiki is indicated after a reviewing process established by the OECD: a) under development, b) under review by the EAGMST, c) approved by the EAGMST, or d) Endorsed by the Working Group of the National Coordinators of the Test Guideline Programme (WNT) and the Working Party on Hazard Assessment (WPHA) ${ }^{27}$.

\section{Assay methods}

Assay methods to investigate KEs in AOPs may be widely standardized methods at the international or national level or more recently developed methods that have not undergone formal validation, but which are well described and accepted by the scientific community within the context for which they are to be applied ${ }^{27}$.

An AOP may inform a number of analytical domains during decision-making: (1) priority setting for testing the chemicals to be regulated; (2) grouping the chemicals according to common toxicity pathways, data needs, and consideration of non-testing methods, such as read-across and (quantitative) structure-activity relationship ((Q)SAR); and (3) priority setting for informed risk assessment by considering qualitative and quantitative determinations of human and ecological relevance, such as exposure, dose-response extrapolations, and the potential for combined effects of chemicals ${ }^{3,28}$.

\section{Prioritization/screening}

To prioritize substances that should undergo evaluation, confidence in the biological plausibility of the AOP must be solid, particularly in the assay(s) that characterize the $\mathrm{MIE}^{3,42}$. Initially, less complex and faster screening methods are used to examine the biological activity of the chemicals ${ }^{29}$. The substances that result positive are ranked from the least to the most potent and will proceed to a more complex and detailed testing evaluation. Full understanding of the dose-response of each KE or quantitative KERs is not necessary for this type of application ${ }^{3,43}$. Even putative, partially characterized AOPs can furnish sufficient data for the early steps of chemical screening by either filling data gaps or 
predicting chemical effects based on reliable assays ${ }^{27}$. Mechanistic information described in AOPs not only facilitates its application in priority setting and assessment of chemical hazards, but also contributes to safety assessment in the drug discovery process ${ }^{44,45}$.

\section{Quantitative Structure-Activity Relationship ((Q)SAR),} Read-across, and In Silico methods

Few chemicals are so isolated in their properties or exposure characteristics that their potential toxicity and MoA cannot be estimated from similar class members. In fact, chemicals can be grouped by similar characteristics such as bioavailability, reactivity, and metabolism, which may also be obtained through non-testing approaches like (Q)SARs or already available testing data ${ }^{3,46}$. A chemical that is first in its respective class, whether on the basis of its molecular structure, biological targets, or MoA, will require more extensive evaluation than the subsequent members of that class.

The read-across approach may gather sufficient information to guide informed decisions about the risk imposed by a particular chemical. With the growing number of synthetic chemicals awaiting evaluation and the practical limitations of the different national regulatory corps that evaluate them, the desire to exploit read-across approaches to address data gaps has increased, but acceptance has been restrained, especially for complex endpoints such as the endpoints that depend on repeated dose toxicity ${ }^{47}$. This happens probably because read-across has been traditionally anchored on chemical structural similarity without a meaningful way of assimilating a biological parallel characteristic. In these circumstances, if an AOP is available for a complex endpoint, in vitro data to characterize the MIE and KEs could be generated to corroborate read-across predictions for an in vivo $\mathrm{AO}^{3,43,47}$. Decades of data generation on exposure and toxicity, dose-response, and in vivo end-points, which are currently available in online databases, may be sufficient to conduct focused data mining to guide regulatory decisions $^{5,42}$. In this context, in silico tools may help to organize, to compare, and to retrieve stored information from past and current research and thus provide massive and organized knowledge to build predictive models $\mathrm{s}^{33,45}$.

\section{Risk assessment}

Risk assessment requires that the assays be quantitatively validated at each KE and KER to justify, for example, the read-across prediction within a chemical category ${ }^{3}$. This quantitative understanding may be measured with regard to the magnitude and duration of the changes, which should be defined in terms of correlations, dose-response relationships, dose-dependent transitions, or points-of-departure ${ }^{29,30,31}$. Therefore, when an AOP is applied to characterize human risk, one has to acquire a quantitative understanding of not only the MIE and the AO, but also the critical KEs along the pathway, particularly their respective dose-responses and temporal concordances, that is, the KERs.

For risk assessment, the tolerated level of uncertainty of an AOP must be low, and the WoE must be high. Risk assessment will be more robust in the case of an AOP for which extensive downstream KEs are available along with quantitative data on exposure, dose-response, and pharmacokinetics. As indicated previously, putative or qualitative AOPs, for which there is no sufficient quantitative knowledge of the complex biological interactions and dose-responses, may also provide valuable information to identify data gaps, indicating low tier screening and informing hypothesis-driven testing assays ${ }^{3,24}$.

Once an AOP has helped to identify and to develop the necessary experimental (in vivo, in vitro, in chemico) assays and non-testing (in silico, read-across) approaches to support regulatory decisions, an objective tool is needed to interpret the corresponding results and to build prediction models so as to facilitate their application in regulatory decision-making $3,25,48,49,50$. This role may be filled in by the Integrated Approaches to Testing and Assessment (IATA), which is an iterative approach to answer well-defined questions in a specific regulatory context, taking the acceptable level of uncertainty associated with the needed decision into account ${ }^{49,51}$. If the available evidence is insufficient to address a given regulatory purpose, whether it be for priority setting, read-across, or hazard identification, the IATA may also indicate what type of data is required to make the decision effective while reducing dependence on animal testing ${ }^{3,49}$ (Figure 2).

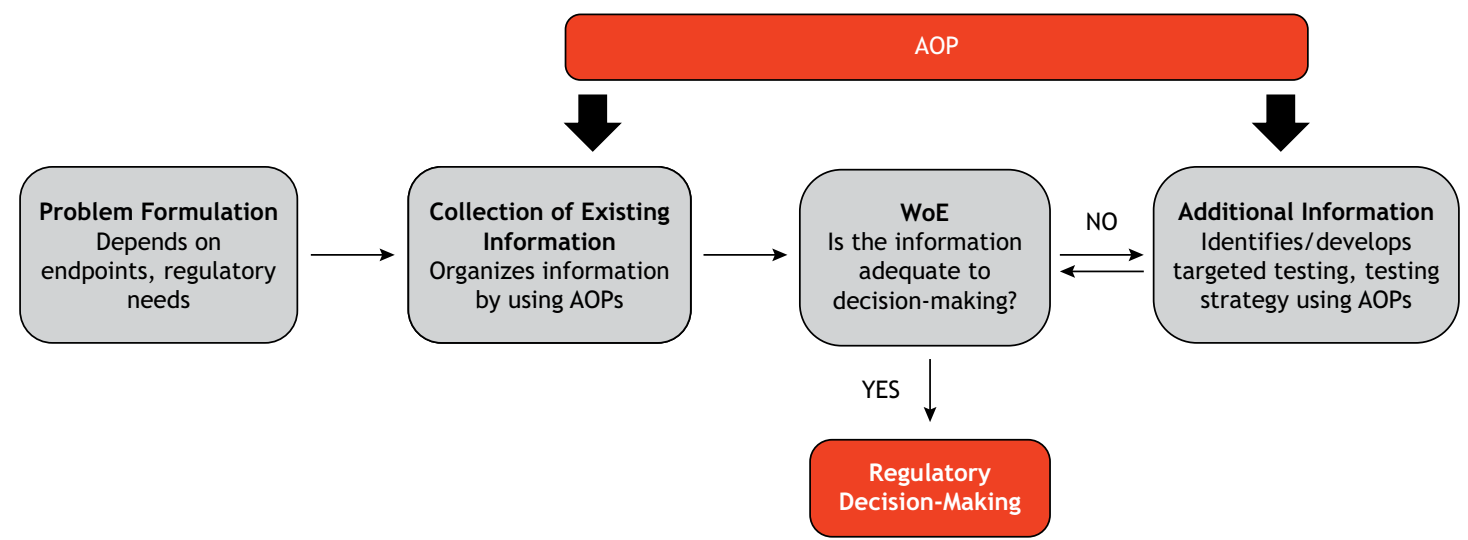

Source: Adapted from Organisation for Economic Co-operation and Development (OECD), $2017^{51}$.

Figure 2. The Integrated Approaches to Testing and Assessment (IATA) integrates AOPs and provides mechanistic information to answer problem formulations in order to facilitate regulatory decision-making. 
As new chemicals become available in the market, scientific research is further developed, and toxicological information is added to the literature. In this context, AOPs are developed by allowing continuous integration of the available data and ponderation about its relevance, a process based on critical assessment of the evidences, including submission to approval by the SAAOP or OECD expert groups.

\section{Case examples}

Herein, case examples of AOPs that have already been endorsed by the $O E C D^{25}$ are presented, namely: (1) skin sensitization, (2) endocrine disruption, and (3) mitochondrial dysfunction. We will highlight how they can contribute to risk assessment and regulatory decision-making by decreasing the use of traditional toxicity tests.

\section{Example 1 - Skin sensitization}

Traditionally, tests to determine skin sensitization have involved animal models, including the Mouse Local Lymph Node Assay (LLNA), the Buehler Assay, and the Guinea Pig Maximization Test ${ }^{52,53}$. To comply with the 3 Rs policy, non-animal methods have been proposed to assess potential chemical sensitizers ${ }^{54,55}$. In 2016, the Brazilian National Council for the Control of Animal Experimentation (Conselho Nacional de Controle de Experimentação Animal - CONCEA) indicated two validated alternative tests to replace the in vivo methods for evaluating the potential for skin sensitization: a) the OECD TG 442C - In chemico Skin Sensitization: Direct Peptide Reactivity Assay (DPRA), and b) the OECD TG 442D - Skin sensitization in vitro: ARE-Nrf2 Luciferase Test Method ${ }^{44}$. As documented in the AOP-Wiki AOP N. 40 "The adverse outcome pathway for skin sensitization initiated by covalent binding to proteins"56, the sensitizer binds to nucleophilic proteins to activate keratinocytes that lead to inflammatory cytokine release (e.g., IL-18) and dendritic cell activation. Immature dendritic cells internalize the sensitizer-protein complex and present them to the T-cells in the proximal lymph nodes. These cells differentiate into proliferating specific memory T-cells that can efficiently respond to the next contact with the corresponding sensitizer, thereby triggering the $\mathrm{AO}$ in the form of contact dermatitis (Figure 3) $32,56,57,58$.

The recent report by Bezerra et al. ${ }^{60}$ exemplifies a practical contribution toward the applicability of the existing OECD guidance $^{59}$ for skin AOPs and the IATA. These authors evaluated the immunotoxicity of carbon nanotubes containing titanium dioxide and of fullerene. By using in vitro assays for accurate assessment of skin sensitization, these authors indicated that the nanomaterials were internalized into keratinocytes (KE1), interacted with skin protein-like molecules (KE2), and stimulated inflammatory cytokine production by monocytic cells (KE3) ${ }^{60}$. Accordingly, the nanomaterials were deemed to be skin sensitizers in vitro, indicating that they should be considered for further higher tier studies to support risk assessment, including exposure and dose-response evaluations.

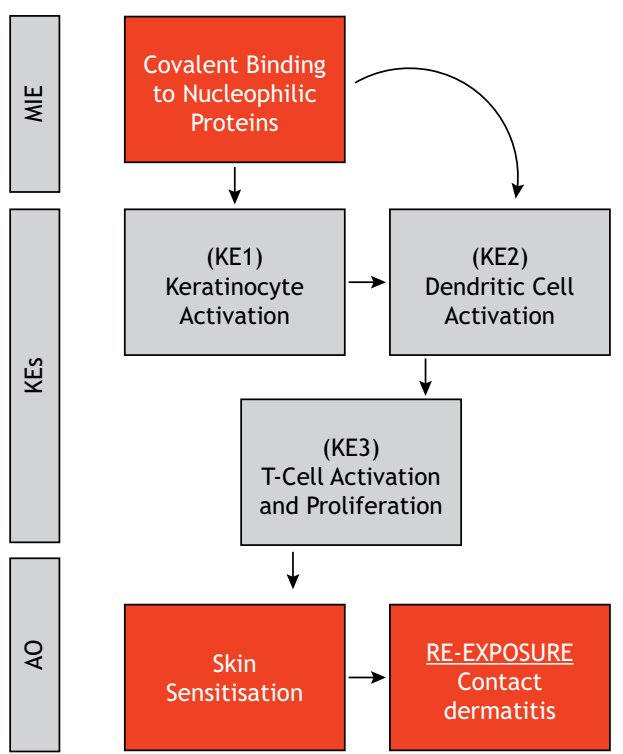

Source: Adapted from AOP Wiki, $2019^{56}$ and Organisation for Economic Co-operation and Development (OECD), $2016^{59}$.

Figure 3. AOP for skin sensitization. Binding of the sensitizer to skin proteins (MIE) activates keratinocytes (KE1), dendritic cells (KE2), and T cells (KE3), successively. Activated memory T-cells may subsidize eventual contact dermatitis $(\mathrm{AO})$ in case of re-exposure.

\section{Example 2 - Endocrine disruption}

Humans are exposed to the so-called endocrine disruptors, various substances or mixture of substances that can alter the synthesis, excretion, transport, binding, action, or elimination of natural hormones at certain doses, leading to adverse effects on the organism, its offspring, or the population ${ }^{61,62}$. For example, activation of steroids, thyroid, or peroxisome proliferator-activated receptors, such as the PPARa, can trigger endocrine disruption ${ }^{63}$. The AOP-Wiki AOP N. 18 "PPARa activation leading to impaired fertility", describes in utero PPARa activation as the MIE for toxicity toward the male reproductive system ${ }^{64}$. This MIE is followed by the KEs indicated in the Figure 4. Phthalates are examples of chemicals with PPAR-mediated activity; metabolization of phthalate diesters to hydrolytic monoesters seems to play a central part in PPAR activation and its toxicological effects ${ }^{65}$. Due to their endocrine disrupting potential, four phthalates (bis(2-ethylhexyl)-phthalate (DEHP), dibutyl-phthalate (DBP), benzyl-butyl-phthalate (BBP), and diisobutyl-phthalate (DIBP) had their use in plasticized materials such as toys and childcare articles restricted by the European Union in $2018^{66}$.

Applied to ecotoxicology, the AOP-Wiki AOP N. 23 "Androgen receptor agonism leading to reproductive dysfunction (in repeat-spawning fish)" ${ }^{\prime 67}$ describes biological responses to androgen receptor (AR) activation. Binding of a determined chemical to the $A R$ reduces circulating gonadotrophins and the synthesis of steroid hormones by the gonads and of vitellogenin by the liver. In this context, vitellogenin uptake by the oocyte decreases, which impairs its development. Over time, reduction of the total amount of eggs released by the females can influence the size of fish population. Consequently, the local food web is modified. 


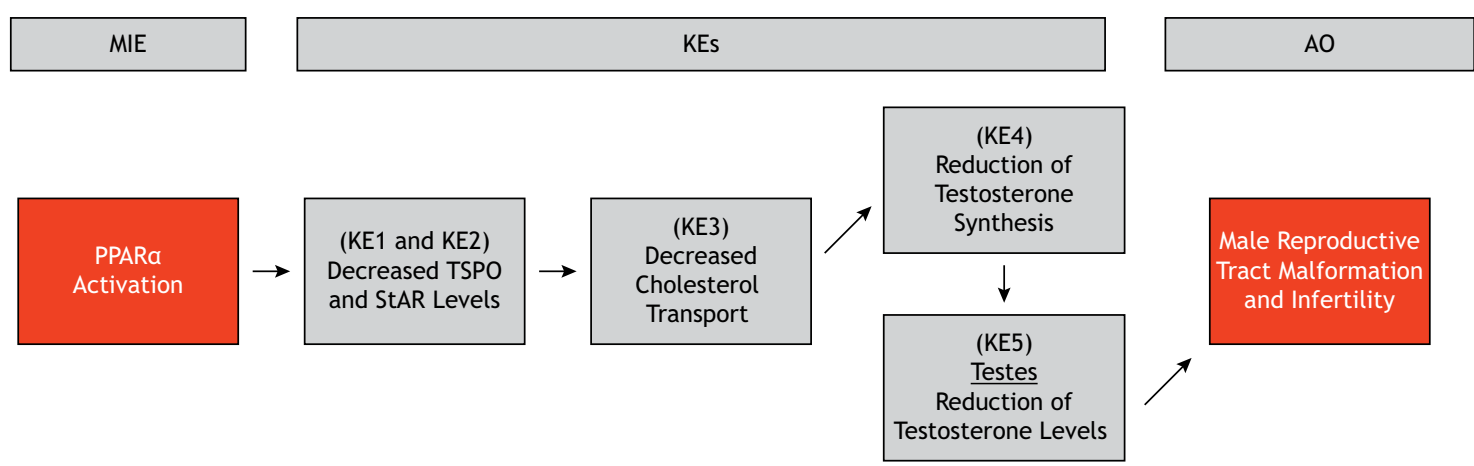

Source: Adapted from AOP Wiki N. 18, $2016^{63}$.

Figure 4. AOP for endocrine disruption in male rodents. PPARa activation (MIE) decreases TSPO and StAR protein levels (KE1, K2) and reduces cholesterol transport (KE3), thus impairing testosterone synthesis (KE4) and its testicular levels (KE5); the risk of malformation of the male reproductive tract and infertility (AOs) increases.

This AOP was developed from evidence obtained with three fish species, but some of its aspects are conserved across vertebrate species $^{67}$. For example, on the basis of evidence collected from rodents, it shares the same KE of decreased 17-beta-estradiol synthesis by ovarian granulosa cells, as indicated by AOP-Wiki AOP N. 7 "Aromatase (Cyp19a1) reduction leading to impaired fertility in adult female" ${ }^{68}$.

The U.S. EPA's Endocrine Disruptor Screening Program (EDSP) uses validated methods in a two-tiered approach to screen and to evaluate potential endocrine disruptors in order to assess hazard and risks and ultimately issue regulatory guidance. While Tier 1 comprises in vitro and in vivo assays to evaluate the estrogen, androgen, and thyroid hormone systems, Tier 2 tests may be requested to characterize dose-response relationships and adverse effects on mammals, fish, amphibians, and birds (in vivo assays) of chemicals having potential endocrine activity ${ }^{69}$. When adjusted to this context, AOP frameworks can facilitate the WoE determination of a chemical's potential endocrine activity, identify data gaps, aid study design, direct assay development, and guide testing strategies, which speeds analytical processes and may save costs and experimental efforts. In cases where computational methods are validated, they may be considered as alternatives to specific assays or endpoints ${ }^{69,70}$.

\section{Example 3 - Mitochondrial dysfunction}

Besides their role in bioenergetics, mitochondria participate in various other cellular activities, including programmed cell death and signal transduction ${ }^{71,72}$. Mitochondria are present not only in liver, a main target organ in toxicity investigations, but also in tissues that have high-energy demand, including muscles and brain. In the latter organ, mitochondria play a critical role in membrane excitability, neurotransmission, and plasticity of neurons. Therefore, association of mitochondrial dysfunction with impairment of neurological functions as in the case of Parkinson's disease is not surprising ${ }^{73,74,75,76}$. As documented in the AOP-Wiki, the AOP-Wiki N. 3 "Inhibition of the mitochondrial complex I of nigro-striatal neurons leads to parkinsonian motor deficits"77 describes that binding of an inhibitor agent such as the 1-methyl-4-phenyl-1,2,3,6-tetrahydropyridine (MPTP) to the complex I of the mitochondrial electron transport chain is the MIE (Figure 5). The MPTP molecule is structurally similar to paraquat (1,1'-dimethyl-4,4'- bipyridine), an herbicide that has been suspected to induce Parkinson's disease in animals and humans ${ }^{78}$ and which has been recently banned from the Brazilian market by the National Health Surveillance Agency (Agência Nacional de Vigilância Sanitária - Anvisa) due to its toxicological potential ${ }^{79}$.

Our laboratory has proposed the AOP-Wiki N. $335^{80}$ for chemically induced rat urinary bladder tumors on the basis of successive animal and in vitro studies in which the herbicide diuron was used as chemical stressor ${ }^{81,82,83}$. This proposal was based on considerable amount of evidence that linked long-term

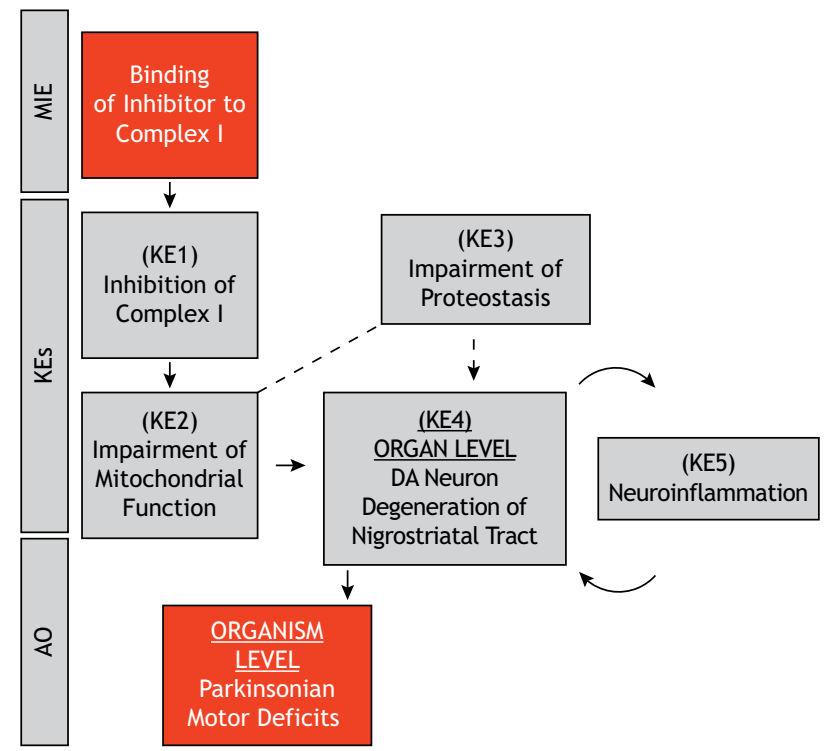

Source: Adapted from AOP Wiki N. 3, $2019^{77}$.

Figure 5. AOP for mitochondrial dysfunction. Binding of a compound to the complex I (MIE) of the electron transport chain inactivates such chain (KE1), impairs mitochondrial activity (KE2), and potentially leads to proteostasis injury (KE3). In the brain, degeneration of the dopaminergic (DA) neurons (KE4) of the nigrostriatal tract is accompanied by neuroinflammation (KE5) and parkinsonian motor disorders (AO). 
exposures to some chemicals with KEs like urothelial cytotoxicity, cell proliferation, hyperplasia, and benign and malignant tumors (AOs) ${ }^{84,85}$. The AOP-Wiki N. 335, which is currently under development, hypothesizes that the MIE in this pathway consists of mitochondrial disfunction induced by urothelial stressors. To verify human relevance, this putative MIE is currently under scrutiny in in vitro approaches that test human 1T1 urothelial bladder cells exposed to the herbicide diuron and its main metabolites ${ }^{86}$.

\section{CONCLUSIONS}

AOP frameworks represent a clear scientific progress of chemical safety assessment and regulatory toxicology and are largely based on knowledge about toxicological mechanisms and modes of action. Because these frameworks have been only recently developed ${ }^{13,16,17,18,22}$, their full use for regulatory purposes worldwide remains to be accomplished. However, progressive application of AOPs by regulatory agencies can be foreseen in the same way that MoA frameworks have been incorporated into safety assessments for regulatory aims since they were proposed in 20016,9. Being more comprehensive and informative than MoA frameworks, AOPs may allow toxicological information to be shared between the scientific community and regulatory agencies more effectively via easy-to-access systematic knowledge construction and database.

Limitations have to be overcome before AOP frameworks can be effectively employed in regulatory practices. Examples of such limitations are chemically induced outcomes involving more than one MIE and numerous KEs, which can hardly be fully explored in a single AOP, not to mention the events that may trigger compensatory mechanisms or feedbacks that can modify the downstream evolution of a putative framework. Nevertheless, continuous collaborative interaction between AOP developers within the scientific community and the regulatory corps toward AOPs development will support the advancement of toxicological sciences at various levels, based on real-world human and environmental health issues, regardless of immediate regulatory purposes.

\section{REFERENCES}

1. Russell WMS, Burch RL. The principles of humane experimental technique. London: Methuen; 1959.

2. Garcia-Reyero N. Are adverse outcome pathways here to stay? Environ Sci Technol. 2015;49(1):3-9. https://doi.org/10.1021/es504976d

3. Patlewicz G, Simon TW, Rowlands JC, Budinsky RA, Becker RA. Proposing a scientific confidence framework to help support the application of adverse outcome pathways for regulatory purposes. Regul Toxicol Pharmacol. 2015;71(3):463-77. https://doi.org/10.1016/j.yrtph.2015.02.011

4. Krewski $\mathrm{D}$, Acosta Jr D, Andersen $\mathrm{M}$, Anderson $\mathrm{H}$, Bailar 3rd JC, Boekelheide $\mathrm{K}$ et al. Toxicity testing in the 21st century: a vision and a strategy. J Toxicol Environ Health B Crit Rev. 2010;13(2-4):51-138. https://doi.org/10.1080/10937404.2010.483176

5. Pastoor TP, Bachman AN, Bell DR, Cohen SM, Dellarco M, Dewhurst IC et al. A 21st century roadmap for human health risk assessment. Crit Rev Toxicol. 2014;44(Suppl.3):1-5. https://doi.org/10.3109/10408444.2014.931923

6. Boobis AR, Cohen SM, Dellarco V, McGregor D, Meek MEB, Vickers $C$ et al. IPCS framework for analyzing the relevance of a cancer mode of action for humans. Crit Rev Toxicol. 2006;36(10):781-92. https://doi.org/10.1080/10408440600977677

7. Boobis AR, Doe JE, Heinrich-Hirsch B, Meek ME, Munn S, Ruchirawat $M$ et al. IPCS framework for analyzing the relevance of a noncancer mode of action for humans. Crit Rev Toxicol. 2008;38(2):87-96. https://doi.org/10.1080/10408440701749421
8. National Research Council - NRC. Toxicity testing for assessment of environmental agents: interim report. Washington: National Research Council; 2006.

9. Sonich-Mullin C, Fielder R, Wiltse J, Baetcke K, Dempsey $J$, Fenner-Crisp P et al. IPCS conceptual framework for evaluating a mode of action for chemical carcinogenesis. Regul Toxicol Pharmacol. 2001;34(2):146-52. https://doi.org/10.1006/rtph.2001.1493

10. Linkov I, Fox-Lent C, Read L, Allen CR, Arnott JC, Bellini $\mathrm{E}$ et al. Tiered approach to resilience assessment. Risk Anal. 2018;38(9):1772-80. https://doi.org/10.1111/risa.12991

11. National Research Council - NRC. Toxicity testing in the 21sth century: a vision and a strategy. Washington: The National Academies; 2007.

12. Meek M. AOPs in hazard characterization for human health. Curr Opin Toxicol. 2017;3:80-6. https://doi.org/10.1016/j.cotox.2017.06.002

13. Organisation for Economic Co-operation and Development - OECD. Users' handbook supplement to the guidance document for developing and assessing AOPs. Paris: Organisation for Economic Co-operation and Development; 2016.

14. Meek M. International experience in addressing combined exposures: increasing the efficiency of assessment. Toxicology. 2013;313(2-3):185-9. https://doi.org/10.1016/j.tox.2012.09.015

15. Meek MEB, Palermo CM, Bachman AN, North CM, Lewis RJ. Mode of action human relevance (species concordance) framework: evolution of the Bradford Hill considerations and comparative analysis of weight of evidence. J Appl Toxicol. 2014;34(6):595-606. https://doi.org/10.1002/jat.2984 
16. Vinken $M$, Knapen D, Vergauwen L, Hengstler JG, Angrish M, Whelan M. Adverse outcome pathways: a concise introduction for toxicologists. Arch Toxicol. 2017;91(11):3697-707. https://doi.org/10.1007/s00204-017-2020-z

17. Vinken $M$. Taking adverse outcome pathways to the next level. Toxicol In Vitro. 2018;50:a1-a2. https://doi.org/10.1016/j.tiv.2018.03.017

18. Ankley GT, Bennett RS, Erickson RJ, Hoff DJ, Hornung MW, Johnson RD et al. Adverse outcome pathways: a conceptual framework to support ecotoxicology research and risk assessment. Environ Toxicol Chem. 2010;29(3):730-41. https://doi.org/10.1002/etc.34

19. Organisation for Economic Co-operation and Development OECD. Proposal for a template and guidance on developing and assessing the completeness of adverse outcome pathways. Paris: Organisation for Economic Co-operation and Development; 2012.

20. Organisation for Economic Co-operation and Development - OECD. Adverse outcome pathway knowledge base. Paris: Organisation for Economic Co-operation and Development; 2020[access Sept 19, 2020]. Available from: https: //aopkb. oecd.org/index.html

21. Organisation for Economic Co-operation and Development - OECD. Adverse outcome pathway Wiki. Paris: Organisation for Economic Co-operation and Development; 2013[access Sept 19, 2020]. Available from: https://aopwiki.org/

22. Organisation for Economic Co-operation and Development - OECD. Proposal for a template and guidance on developing and assessing the completeness of adverse outcome pathways. Paris: Organisation for Economic Co-operation and Development; 2012[access Sept 19, 2020]. Available from: http://www.oecd.org/chemicalsafety/ testing/49963554.pdf

23. Organisation for Economic Co-operation and Development OECD. Lists of projects on the AOP development programme workplan. Paris: Organisation for Economic Co-operation and Development; 2016[access Sept 19, 2020]. Available from: http://www.oecd.org/chemicalsafety/testing/proje cts-adverse-outcome-pathways.htm

24. Organisation for Economic Co-operation and Development - OECD. Revised guidance document on developing and assessing adverse outcome pathways: series on testing and assessment 184. Paris: Organisation for Economic Co-operation and Development; 2017.

25. Organisation for Economic Co-operation and Development - OECD. Adverse outcome pathway wiki: OECD status: SAAOP status: recent AOP. Paris: Organisation for Economic Co-operation and Development; 2013[access Sept 19, 2020]. Available from: https://aopwiki.org/ aops?direction=asc\&sort=oecd_status

26. Christopher M, Antony J, Inthirany T, Ann M. EPA's DSSTox database: history of development of a curated chemistry resource supporting computational toxicology research. Comput Toxicol. 2019;12:1-15. https://doi.org/10.1016/j.comtox.2019.100096
27. Coady K, Browne P, Embry M, Hill 3rd T, Leinala E, Steeger $T$ et al. When are adverse outcome pathways and associated assays fit for purpose for regulatory decision-making and management of chemicals? Integr Environ Assess Manag. 2019;15(4):633-47. https://doi.org/10.1002/ieam.4153

28. Meek M, Boobis A, Cote I, Dellarco V, Fotakis G, Munn $S$ et al. New developments in the evolution and application of the WHO/IPCS framework on mode of action/species concordance analysis. J Appl Toxicol. 2014;34(1):1-18. https://doi.org/10.1002/jat.2949

29. Vinken M. Adverse outcome pathways as tools to assess drug-induced toxicity. Methods Mol Biol. 2016;1425:325-37. https://doi.org/10.1007/978-1-4939-3609-0_14

30. Villeneuve D, Crump D, Garcia-Reyero N, Hecker M, Hutchinson TH, LaLone CA et al. Adverse outcome pathway (AOP) development I: strategies and principles. Toxicol Sci. 2014;142(2):312-20. https://doi.org/10.1093/toxsci/kfu199

31. Villeneuve D, Crump D, Garcia-Reyero $\mathrm{N}$, Hecker M, Hutchinson TH, LaLone CA et al. Adverse outcome pathway development II: best practices. Toxicol Sci. 2014;142(2):321-30. https://doi.org/10.1093/toxsci/kfu200

32. Vinken $M$. The adverse outcome pathway concept: a pragmatic tool in toxicology. Toxicology. 2013;312(1):158-65. https://doi.org/10.1016/j.tox.2013.08.011

33. Wittwehr C, Aladjov H, Ankley G, Byrne HJ, Knecht J, Heinzle E et al. How adverse outcome pathways can aid the development and use of computational prediction models for regulatory toxicology. Toxicol Sci. 2017;155(2):326-36. https://doi.org/10.1093/toxsci/kfw207

34. Edwards SW, Tan YM, Villeneuve DL, Meek ME, McQueen CA. Adverse outcome pathways: organizing toxicological information to improve decision making. J Pharmacol Exp Ther. 2016;356(1):170-81. https://doi.org/10.1124/jpet.115.228239

35. Bal-Price A, Lein P, Keil K, Sethi S, Shafer T, Barenys $M$ et al. Developing and applying the adverse outcome pathway concept for understanding and predicting neurotoxicity. Neurotoxicology. 2017;59:240-55. https://doi.org/10.1016/j.neuro.2016.05.010

36. Fay KA, Villeneuve DL, LaLone CA, Song Y, Tollefsen KE, Ankley GT. Practical approaches to adverse outcome pathway development and weight-of-evidence evaluation as illustrated by ecotoxicological case studies. Environ Toxicol Chem. 2017;36(6):1429-49. https://doi.org/10.1002/etc. 3770

37. Perkins E, Garcia-Reyero N, Edwards S, Wittwehr C, Villeneuve $D$, Lyons $D$ et al. The adverse outcome pathway: a conceptual framework to support toxicity testing in the twenty-first century. In: Hoeng J, Peitsch MC, editors. Computational systems toxicology. Basingstoke: Springer; 2015. p.1-29. 
38. Russom CL, Lalone CA, Villeneuve DL, Ankley GT. Development of an adverse outcome pathway for acetylcholinesterase inhibition leading to acute mortality. Environ Toxicol Chem. 2014;33(10):2157-69. https://doi.org/10.1002/etc. 2662

39. Knapen D, Angrish MM, Fortin MC, Katsiadaki I, Leonard M, Margiotta-Casaluci L et al. Adverse outcome pathway networks I: development and applications. Environ Toxicol Chem. 2018;37(6):1723-33. https://doi.org/10.1002/etc. 4125

40. Hill AB. The environment and disease: association or causation? Proc R Soc Med. 1965;58(5):295-300.

41. Becker RA, Ankley GT, Edwards SW, Kennedy SW, Linkov I, Meek B et al. Increasing scientific confidence in adverse outcome pathways: application of tailored Bradford-Hill considerations for evaluating weight of evidence. Regul Toxicol Pharmacol. 2015;72(3):514-37. https://doi.org/10.1016/j.yrtph.2015.04.004

42. Embry MR, Bachman AN, Bell DR, Boobis AR, Cohen SM, Dellarco $M$ et al. Risk assessment in the 21st century: roadmap and matrix. Crit Rev Toxicol. 2014;44(Supl.3):6-16. https://doi.org/10.3109/10408444.2014.931924

43. Patlewicz G, Simon T, Goyak K, Phillips RD, Rowlands $J C$, Seidel SD et al. Use and validation of $\mathrm{HT} / \mathrm{HC}$ assays to support 21st century toxicity evaluations. Regul Toxicol Pharmacol. 2013;65(2):259-68. https://doi.org/10.1016/j.yrtph.2012.12.008.

44. Ministério da Ciência, Tecnologia, Inovações e Comunicações (BR). Resolução normativa $\mathrm{N}^{\circ} 31$, de 18 de agosto de 2016. Reconhece métodos alternativos ao uso de animais em atividades de pesquisa no Brasil. Diário Oficial União. Aug 19, 2016.

45. Raies AB, Bajic VB. In silico toxicology: computational methods for the prediction of chemical toxicity. Wiley Interdiscip Rev Comput Mol Sci. 2016;6(2):147-72. https://doi.org/10.1002/wcms. 1240

46. Rusyn I, Sedykh A, Low Y, Guyton KZ, Tropsha A. Predictive modeling of chemical hazard by integrating numerical descriptors of chemical structures and short-term toxicity assay data. Toxicol Sci. 2012;127(1):1-9. https://doi.org/10.1093/toxsci/kfs095

47. Ball N, Bartels M, Budinsky R, Klapacz J, Hays S, Kirman $C$ et al. The challenge of using read-across within the EU Reach regulatory framework; how much uncertainty is too much? Dipropylene glycol methyl ether acetate, an exemplary case study. Regul Toxicol Pharmacol. 2014;68(2):212-21. https://doi.org/10.1016/j.yrtph.2013.12.007

48. Bal-Price A, Crofton KM, Sachana M, Shafer TJ, Behl M, Forsby A et al. Putative adverse outcome pathways relevant to neurotoxicity. Crit Rev Toxicol. 2015;45(1):83-91. https://doi.org/10.3109/10408444.2014.981331

49. Tollefsen KE, Scholz S, Cronin MT, Edwards SW, Knecht J, Crofton $\mathrm{K}$ et al. Applying adverse outcome pathways (AOPs) to support integrated approaches to testing and assessment
(IATA). Regul Toxicol Pharmacol. 2014;70(3):629-40. https://doi.org/10.1016/j.yrtph.2014.09.009

50. Worth AP, Patlewicz G. Integrated approaches to testing and assessment. Adv Exp Med Biol. 2016;856:317-42. https://doi.org/10.1007/978-3-319-33826-2_13

51. Organisation for Economic Co-operation and Development - OECD. Guidance document for the use of adverse outcome pathways in developing integrated approaches to testing and assessment (IATA). Paris: Organisation for Economic Co-operation and Development; 2017.

52. Organisation for Economic Co-operation and Development - OECD. OECD guidelines for the testing of chemicals: report test 406: skin sensitisation. Paris: Organisation for Economic Co-operation and Development; 1992.

53. Organisation for Economic Co-operation and Development - OECD. OECD guidelines for the testing of chemicals: report test 429: skin sensitisation: local lymph node assay. Paris: Organisation for Economic Co-operation and Development; 2010.

54. Netzlaff F, Lehr CM, Wertz PW, Schaefer UF. The human epidermis models EpiSkin, SkinEthic and EpiDerm: an evaluation of morphology and their suitability for testing phototoxicity, irritancy, corrosivity, and substance transport. Eur J Pharm Biopharm. 2005;60(2):167-78. https://doi.org/10.1016/j.ejpb.2005.03.004

55. Vecchi R, Dakic V, Mattos G, Rigaudeau AS, Oliveira V, Garcia C et al. Implementation, availability and regulatory status of an OECD accepted reconstructed human epidermis model in Brazil. Vigil Sanit Debate. 2018;6(1):64-71. https://doi.org/10.22239/2317-269x.01055

56. Sharon M, Brigitte L, Coralie D. Covalent protein binding leading to skin sensitisation. Adverse Outcome Pathway Wiki. 2019[access Oct 25, 2020]. Available from: https: / /aopwiki.org/aops/40

57. Maxwell G, Mackay C, Cubberley R, Davies M, Gellatly $\mathrm{N}$, Glavin $\mathrm{S}$ et al. Applying the skin sensitisation adverse outcome pathway (AOP) to quantitative risk assessment. Toxicol In Vitro. 2014;28(1):8-12. https://doi.org/10.1016/j.tiv.2013.10.013

58. Alberts B, Johnson A, Lewis J, Raff M, Roberts K, Walter P. Lymphocytes and the cellular basis of adaptive immunity. In: Alberts B, Johnson A, Lewis J, Morgan D, Raff M, Roberts $K$ et al. editors. Molecular biology of the cell. 4th ed. New York: Garland Science; 2002 [access Oct 25, 2020]. Available from: https: //www.ncbi.nlm.nih.gov/books/NBK26921/

59. Organisation for Economic Co-operation and Development - OECD. Guidance document on the reporting of defined approaches and individual information sources to be used within integrated approaches to testing and assessment (IATA) for skin sensitisation: series on testing \& assessment: report 256. Paris: Organisation for Economic Co-operation and Development; 2016. 
60. Bezerra SF, Rodrigues BS, Silva ACG, Ávila RI, Brito HRG, Cintra ER et al. Application of the adverse outcome pathway (AOP) framework for investigating skin sensitization potential of nanomaterials using new approach methods. Contact Derm. 2021;84(2):64-74. https: //doi.org/10.1111/cod.13669

61. Monneret $C$. What is an endocrine disruptor? C R Biol. 2017;340(9-10):403-5. https://doi.org/10.1016/j.crvi.2017.07.004

62. World Health Organization - WHO. State of the science of endocrine disrupting chemicals 2012: summary for decision-makers. Geneva: World Health Organization; 2013.

63. Vitti M, Emidio G, Carlo M, Carta G, Antonosante A, Artini PG et al. Peroxisome proliferator-activated receptors in female reproduction and fertility. PPAR Res. 2016;2016:1-12. https://doi.org/10.1155/2016/4612306

64. Nepelska M, Grignard E, Munn S. PPARa activation in utero leading to impaired fertility in males. Adverse Outcome Pathway Wiki. 2016[access Oct 25, 2020]. Available from: https://aopwiki.org/aops/18

65. Latini G, Scoditti E, Verrotti A, Felice C, Massaro $M$. Peroxisome proliferator-activated receptors as mediators of phthalate-induced effects in the male and female reproductive tract: epidemiological and experimental evidence. PPAR Res. 2008;2008:1-13. https: / / doi.org/10.1155/2008/359267

66. Safe Guards - SGS. EU expands restriction of phthalates under Reach. News Center. Mar 14, 2019[access Oct 25, 2020]. Available from: https://www.sgs.com/en/ news/2019/01/safeguards-00219-eu-expands-restriction-o f-phthalatesunder-reach

67. Villeneuve D. Androgen receptor agonism leading to reproductive dysfunction (in repeat-spawning fish). Adverse Outcome Pathway Wiki. 2019[access Oct 25, 2020]. Available from: https://aopwiki.org/aops/23

68. Nepelska M, Grignard E, Munn S. Aromatase (Cyp19a1) reduction leading to impaired fertility in adult female. Adverse Outcome Pathway Wiki. 2016[access Oct 25, 2020]. Available from: https://aopwiki.org/aops/7\#aop_title

69. Browne P, Noyes PD, Casey WM, Dix DJ. Application of adverse outcome pathways to US EPA's endocrine disruptor screening program. Environ Health Perspect. 2017;125(9):1-11. https://doi.org/10.1289/EHP1304

70. United States Environmental Protection Agency - US EPA. Weight-of-evidence: evaluating results of EDSP tier 1 screening to identify the need for tier 2 testing. Washington: United States Environmental Protection Agency; 2011.

71. Zolkipli-Cunningham Z, Falk MJ. Clinical effects of chemical exposures on mitochondrial function. Toxicology. 2017;391:90-9. https://doi.org/10.1016/j.tox.2017.07.009

72. West AP. Mitochondrial dysfunction as a trigger of innate immune responses and inflammation. Toxicology. 2017;391:54-63. https://doi.org/10.1016/j.tox.2017.07.016
73. Kann O, Kovacs R. Mitochondria and neuronal activity. Am J Physiol Cell Physiol. 2007;292(2):C641-57. https://doi.org/10.1152/ajpcell.00222.2006

74. Mattson MP, Gleichmann M, Cheng A. Mitochondria in neuroplasticity and neurological disorders. Neuron. 2008;60(5):748-66. https://doi.org/10.1016/j.neuron.2008.10.010

75. Van Laar VS, Berman SB. The interplay of neuronal mitochondrial dynamics and bioenergetics: implications for Parkinson's disease. Neurobiol Dis. 2013;51:43-55. https://doi.org/10.1016/j.nbd.2012.05.015

76. Course MM, Wang X. Transporting mitochondria in neurons. F1000Res. 2016;5:1-10. https://doi.org/10.12688/f1000research.7864.1

77. Bal-Price A, Leist M, Schildknecht S, Tschudi-Monnet $F$, Paini A, Terron A. Inhibition of the mitochondrial complex I of nigro-striatal neurons leads to parkinsonian motor déficits. Adverse Outcome Pathway Wiki. 2019[access Oct 25, 2020]. Available from: https://aopwiki.org/aops/3

78. Vaccari C, El-Dib R, Gomaa H, Lopes LC, Camargo JLV. Paraquat and Parkinson's disease: a systematic review and meta-analysis of observational studies. J Environ Health Toxicol. 2019;22(5-6):172-202. https://doi.org/10.1080/10937404.2019.1659197

79. Agência Nacional de Vigilância Sanitário - Anvisa. Paraquate: Anvisa mantém data para banimento. Agrotóxicos. Sept 15, 2020[access Oct 25, 2020]. Available from: https://www.gov.br/anvisa/pt-br/assuntos/ noticias-anvisa/2020/paraquate-anvisa-mantem-data-p ara-banimento

80. Souza NP, Lima TRR, Pereira LC, Carmargo JLV. AOP for urothelial carcinogenesis due to chemical cytotoxicity by mitochondrial impairment. Adverse Outcome Pathway Wiki. 2020[access Oct 30, 2020]. Available from: https://aopwiki. org/aops/335

81. Rocha MS, Arnold LL, Luiza M, Sartor C, Catalano SMI, Paula A et al. Diuron-induced rat urinary bladder carcinogenesis: mode of action and human relevance evaluations using the international programme on chemical safety framework. Crit Rev Toxicol. 2014;44(5):1-14. https://doi.org/10.3109/10408444.2013.877870

82. Rocha MS, Nascimento MG, Cardoso APF, Lima LAD, Zelandi EA. Cytotoxicity and regenerative proliferation as the mode of action for diuron-induced urothelial carcinogenesis in the rat. Toxicol Sci. 2010;113(1):37-44. https://doi.org/10.1093/toxsci/kfp241

83. Ihlaseh SM, Bailey KA, Hester SD, Jones C, Ren H, Cardoso APF et al. Transcriptional profile of diuron-induced toxicity on the urinary bladder of male wistar rats to inform mode of action. Toxicol Sci. 2011;122(2):330-8. https://doi.org/10.1093/toxsci/kfr108.

84. Cohen SM. Screening for human urinary bladder carcinogens: two-year bioassay is unnecessary. Toxicol Res (Camb). 2018;7(4):565-75. https://doi.org/10.1039/c7tx00294g 
85. Cohen SM, Ohnishi T, Clark NM, He J, Arnold LL. Investigations of rodent urinary bladder carcinogens: collection, processing, and evaluation of urine and bladders. Toxicol Pathol. 2007;35(3):337-47. https://doi.org/10.1080/01926230701197115
86. Lima TRR, Camargo JLV, Pereira LC. Cytotoxicity assessment in human urothelial $1 \mathrm{~T} 1$ cells exposed to diuron and its metabolites. In: Proceddings of $21^{\text {th }}$ Brazilian Congress of Toxicology; Águas de Lindóia, Brazil. São Paulo: Sociedade Brasileira de Toxicologia; 2019.

Acknowledgments

This work was supported by the São Paulo Research Foundation (Fundação de Amparo à Pesquisa do Estado de São Paulo - Fapesp) Grant No. 2017/25402-5 - and the Center for Evaluation of Environmental Impact on Human Health (Núcleo de Avaliação do Impacto Ambiental sobre a Saúde Humana - TOXICAM), Universidade Estadual Paulista (UNESP), Botucatu, SP, Brazil. Ms. Marluci Betini provided technical assistance.

\section{Authors' Contributions}

Lima TRR, Souza NP, Pereira LC, Camargo JLV - Conception, planning (study design), data acquisition, analysis, and interpretation, and writing of the manuscript. Lima TRR, Souza NP - Writing the manuscript. All authors approved the final draft of the manuscript.

Conflict of Interest

Authors have no potential conflict of interest to declare, related to this study's political or financial peers and institutions.

“Attribution-NonCommercial: CC BY-NC” License. With this license you may access, download, copy, print, share, reuse and distribute the articles, provided that for non-commercial use and with the citation of the source, conferring the proper credits of authorship and mention to Visa em Debate. In such cases, no permission is required by the authors or publishers. 